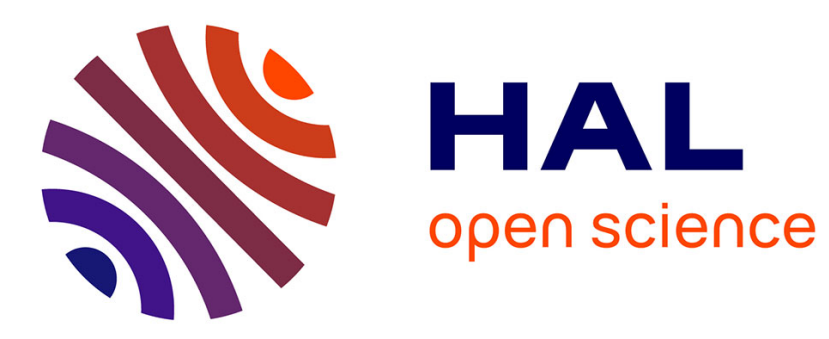

\title{
Light Field Segmentation Using a Ray-Based Graph Structure
}

\author{
Matthieu Hog, Neus Sabater, Christine Guillemot
}

\section{To cite this version:}

Matthieu Hog, Neus Sabater, Christine Guillemot. Light Field Segmentation Using a Ray-Based Graph Structure. ECCV, 2016, Amsterdam, Netherlands. hal-01644651

\section{HAL Id: hal-01644651 \\ https://hal.science/hal-01644651}

Submitted on 22 Nov 2017

HAL is a multi-disciplinary open access archive for the deposit and dissemination of scientific research documents, whether they are published or not. The documents may come from teaching and research institutions in France or abroad, or from public or private research centers.
L'archive ouverte pluridisciplinaire HAL, est destinée au dépôt et à la diffusion de documents scientifiques de niveau recherche, publiés ou non, émanant des établissements d'enseignement et de recherche français ou étrangers, des laboratoires publics ou privés. 


\section{Motivation and Problem}

- We are interested in interactive light field segmentation from a reference view.

- Challenge for light fields: the amount of data to process in order to edit all the views simultaneously.

- In particular, the running time for graph-based approaches, such as graph-cut, increases greatly with the size of the input graph.

- We assume a depth map to be known for each view.

\section{Our Method}

\section{Building The Graph}

- Previous work focuses on representations with one graph node per ray [1]

- Observation: many rays of the light field mainly describe the same content.

- The redundancy is captured by depth estimation.

- We use a single node to represent several rays coming from the same scene point (ray bundles), according to an estimated measure:

$$
\left\{\begin{array}{l}
{\left[x_{i}+\left(s_{i}-s_{j}\right) D\left(s_{i}, t_{i}, x_{i}, y_{i}\right)\right]=x_{j}} \\
{\left[x_{j}+\left(s_{j}-s_{i}\right) D\left(s_{j}, t_{j}, x_{j}, y_{j}\right)\right]=x_{i}}
\end{array}\right.
$$

- To handle occlusions and errors in the depth map, rays that have an incoherent depth measure (free rays) are left in a single node.

- The new neighbourhood relationship are defined using each view neighbourhood. Scene and depth estimates

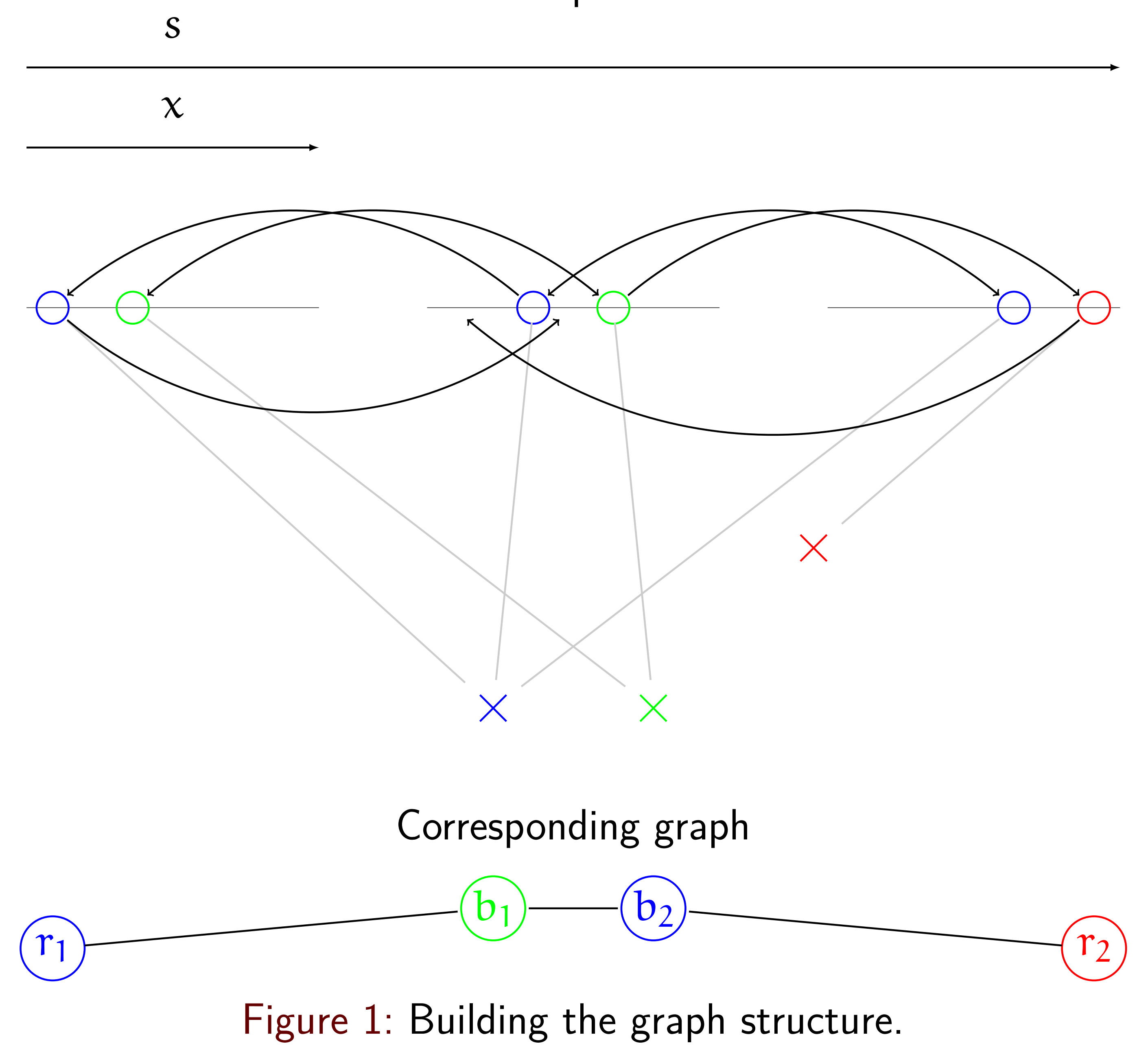

\section{New Energy Terms}

- Ray bundle unary energy term is defined using Gaussian Mixture Models (GMM) on the color and the depth learnt from input scribbles. To compute the free ray unary, the depth component is removed from the GMM:

$$
\mathrm{U}\left(\mathrm{b}_{\mathfrak{i}}\right)= \begin{cases}-\log \left(\mathcal{P}\left(\mathrm{C}\left(\mathrm{b}_{i}\right), \mathrm{D}\left(\mathrm{b}_{i}\right) \mid \mathrm{L}\left(\mathrm{b}_{i}\right)=\alpha\right)\right) & \text { if } \exists \mathrm{r}_{\mathfrak{i}} \in b_{i}, \mathrm{~S}\left(\mathrm{r}_{\mathfrak{i}}\right)=0 \\ \infty & \text { if } \exists \mathrm{r}_{\mathfrak{i}} \in \mathrm{b}_{i}, \mathrm{~S}\left(\mathrm{r}_{\mathfrak{i}}\right)=\alpha \\ 0 & \text { otherwise }\end{cases}
$$

- We define the new neighbourhood relationship using the neighbourhood on each view. Between free rays and ray bundles:

$$
P\left(r_{i} / b_{i}, r_{j}\right)=\delta_{L\left(r_{i} / b_{i}\right) \neq L\left(r_{j}\right)} \exp \left(\frac{-\Delta E\left(C\left(r_{i} / b_{i}\right), C\left(r_{j}\right)\right)}{\sigma_{L a b}}\right)
$$

- Problem: rays at the object boundaries tend to be more connected to the background node they occlude.

- Solution: sum the individual view neighbourhood energy term:
$\left.\mathrm{P}\left(\mathrm{b}_{\mathrm{i}}, \mathrm{b}_{\mathrm{j}}\right)=\delta_{\mathrm{L}\left(\mathrm{b}_{\mathrm{i}}\right) \neq \mathrm{L}\left(\mathrm{b}_{\mathrm{j}}\right)}\right) \mathrm{b}_{\mathrm{j}} \cap \mathcal{N}\left(\mathrm{b}_{\mathrm{i}}\right) \mid \exp \left(-\frac{\Delta \mathrm{E}\left(\mathrm{C}\left(\mathrm{b}_{\mathrm{i}}\right), \mathrm{C}\left(\mathrm{b}_{\mathrm{j}}\right)\right)}{\sigma_{\text {Lab }}}-\frac{\left(\mathrm{D}\left(\mathrm{b}_{\mathrm{i}}\right)-\mathrm{D}\left(\mathrm{b}_{\mathrm{j}}\right)\right)^{2}}{\sigma_{\mathrm{D}}}\right)$

- We use alpha-expansion to minimise the new energy function:

$\varphi_{\mathrm{L}}=\sum_{\mathrm{r}_{i} \in \mathrm{R}} \mathrm{u}\left(\mathrm{r}_{\mathrm{i}}\right)+\sum_{\mathrm{b}_{i} \in \mathrm{B}} \mathrm{u}\left(\mathrm{b}_{\mathrm{i}}\right)$

$$
+m\left(\sum_{\substack{r_{i}, r_{j} \\ r_{i} \in R, r_{j} \in \mathcal{N}\left(r_{i}\right)}} P\left(r_{i}, r_{j}\right)+\sum_{\substack{b_{i}, r_{i} \\ b_{i} \in B, r_{i} \in \mathcal{N}\left(b_{i}\right)}} P\left(b_{i}, r_{i}\right)+\sum_{\substack{b_{i}, b_{j} \\ b_{i} \in B, b_{j} \cap \mathcal{N}\left(b_{i}\right) \neq \emptyset}} P\left(b_{i}, b_{j}\right)\right)
$$

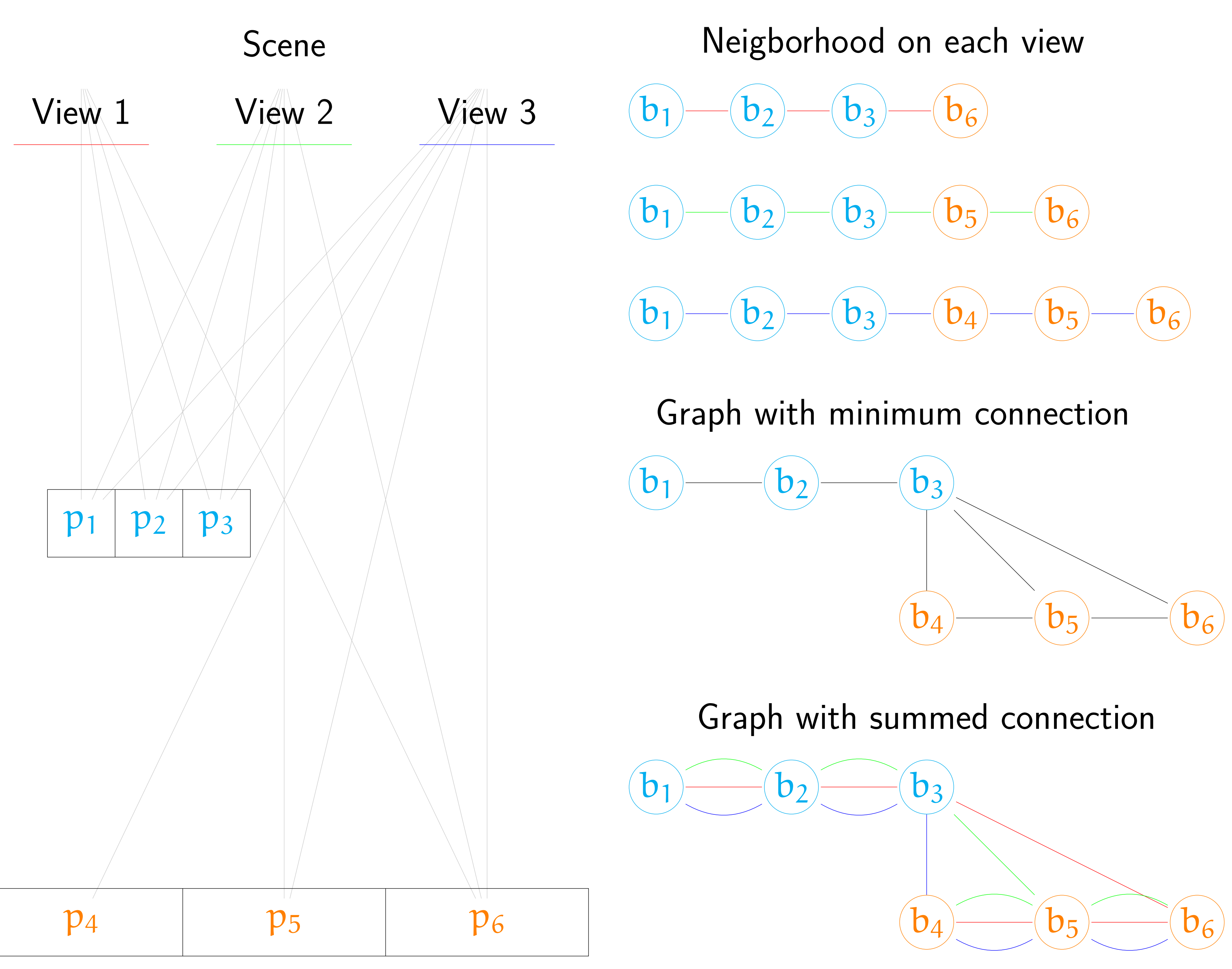

Figure 2: The over-connectivity issue.

\section{Experimental Results}

- Quantitative tests on synthetic dense light field dataset showed our approach to be close to the state of the art [1], with a lower complexity. Our approach also shows to be efficient for dense and sparse real light fields from various sources.

Table 1: Segmentation accuracy comparison.

\begin{tabular}{|c|c|c|c|c|}
\hline Dataset: & Still life 2 & Papillon 2 & Horses 2 & Budha \\
\hline Result of [1]: & 99.3 & 99.4 & 99.3 & 98.6 \\
\hline Our results: & 99.2 & 99.5 & 99.1 & 99.1 \\
\hline Our results w/o depth: & 98.91 & 99.4 & 95.5 & 98.8 \\
\hline
\end{tabular}
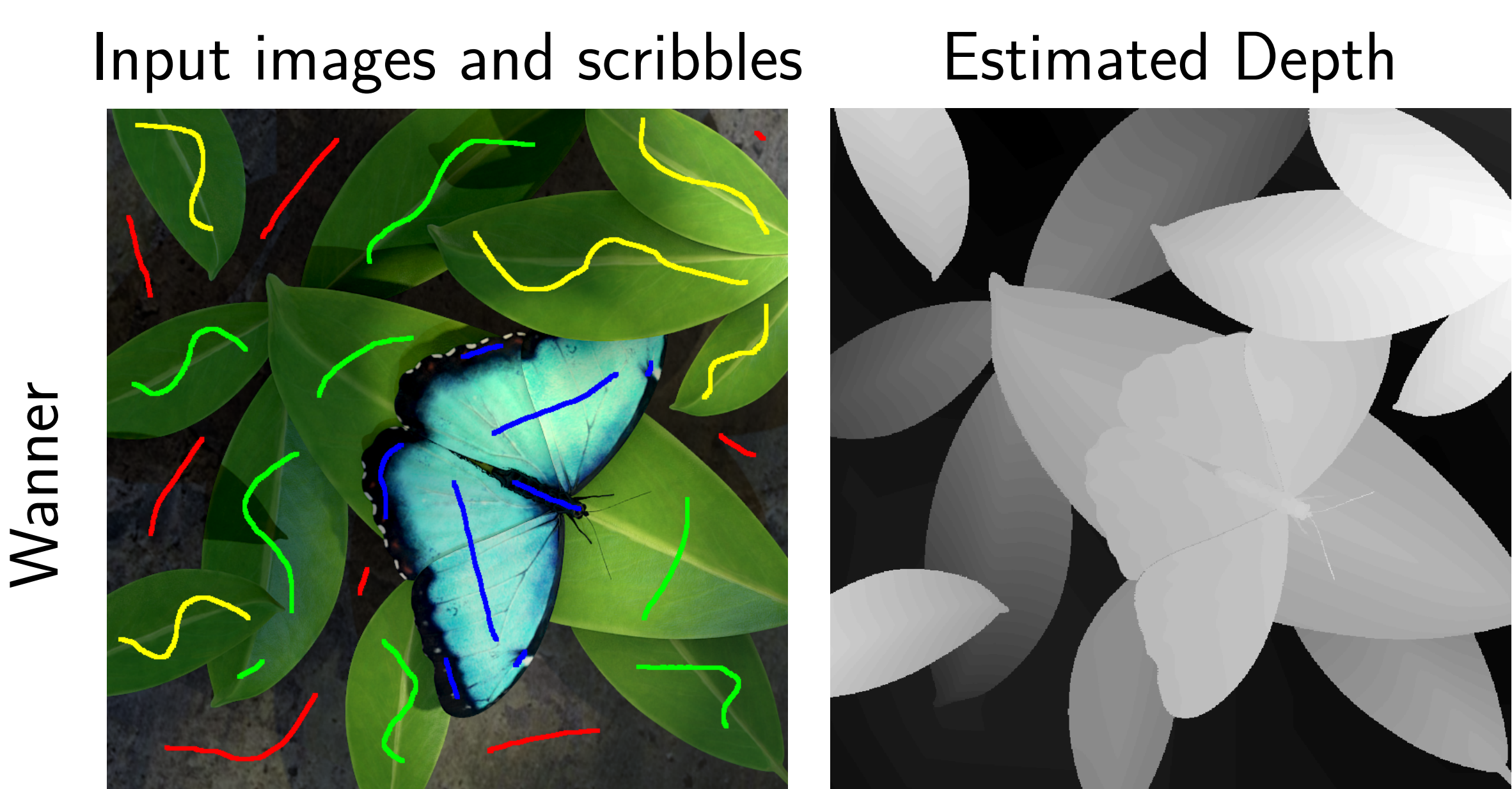

Our results
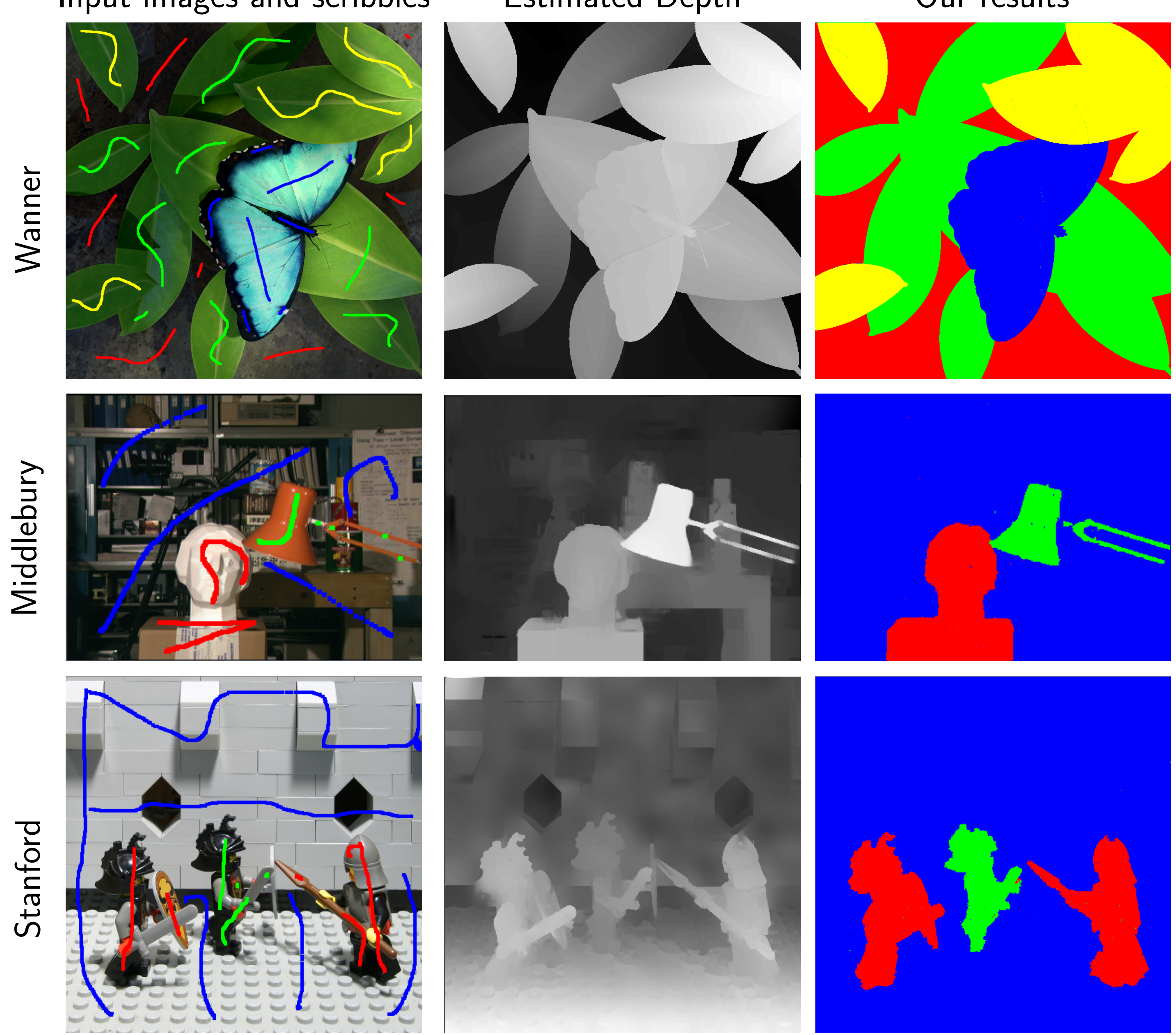

Figure 3: Light-field segmentation results on several datasets.

\section{Summary and Conclusions}

- We proposed a new graph structure that greatly reduces the running time of graph-based algorithm for light fields.

- We demonstrate its efficiency for interactive light field segmentation.

- Limitations: as the amount of depth estimation errors increases, the number of nodes rises and the segmentation coherence decreases.

\section{References}

[1] Wanner et al., Globally consistent multi-label assignment on the ray space of 4d light fields, CVPR 13 